\title{
Vale a pena manter as perguntas sobre ex-moradores residindo no exterior nos censos demográficos brasileiros?
}

\author{
Marden Campos*
}

A produção de estimativas precisas e confiáveis sobre migração internacional é um desafio "histórico" entre os estudiosos de população. Diferentes métodos de estimação têm sido colocados a esse serviço, com base em censos, pesquisas domiciliares, registros de fronteira, cadastros administrativos ou dados consulares. A despeito do avanço significativo nas últimas décadas em termos de produção de dados sobre migração internacional no Brasil, não temos segurança quanto ao volume e, muitas vezes, à direção do saldo migratório internacional do país.

Diversos fatores dificultam a produção de informação sobre a migração e os migrantes internacionais: desde a volatilidade dos fluxos, passando por questões legais e de (in)documentação ${ }^{1}$ dos migrantes até aspectos de ordem conceitual, como a diferenciação entre aqueles que serão classificados como migrantes e os que realizam outras formas de mobilidade espacial.

Esse problema é agravado ainda mais quando abordamos os emigrantes ou indivíduos que deixaram o país. Para os que aqui chegaram, operacionalmente falando, é relativamente mais fácil produzir informações, pois eles aqui estão para serem contados. Por outro lado, produzir dados sobre pessoas que não se encontram mais na população é uma tarefa bem mais complexa.

\footnotetext{
* Universidade Federal de Minas Gerais (UFMG), Belo Horizonte-MG, Brasil (mardencampos@gmail.com; https://orcid. org/0000-0002-7397-5453).

${ }^{1}$ Estimativas dão conta de que mais de $60 \%$ dos emigrantes brasileiros para os Estados Unidos, por exemplo, entraram de forma irregular naquele país (SOARES; FAZITO, 2010).
} 
Os censos demográficos são a fonte mais utilizada para estudos sobre migração internacional em nível nacional, mas até recentemente só forneciam dados sobre imigrantes que aqui residiam. No intuito de produzir informações sobre emigrantes internacionais, em 2010 inseriu-se, pela primeira vez na história dos censos nacionais, um bloco de quesitos destinados a investigar a migração de indivíduos que haviam residido no Brasil e viviam no exterior na época do Censo (Anexo 1). Observa-se, contudo, que esses dados têm sido muito pouco utilizados. Ao nos aproximarmos de um fim de década e da realização de um novo censo decenal, surge a dúvida sobre se deveríamos ou não manter esse tipo de investigação no censo brasileiro.

O presente ensaio visa propor uma reflexão sobre a "utilidade" e "efetividade" das informações sobre ex-moradores residindo no exterior com base na experiência do Censo Demográfico de 2010, apresentando de forma sumária alguns de seus resultados e discutindo metodologicamente o quesito à luz de análises produzidas sobre outras experiências internacionais de uso desse tipo de informação. A presente reflexão não pretende dar um veredicto final sobre a questão, mas provocar a discussão entre os estudiosos do tema sobre quais informações esperaríamos ter à disposição para estudos de migração internacional na próxima década.

\section{A migração internacional recente no Brasil}

A migração de um contingente significativo de população para o exterior é um fenômeno relativamente recente na história do Brasil. Há consenso entre os especialistas de que foi apenas na década de 1980 que se experimentou, pela primeira vez, uma perda líquida de população para o resto do mundo.

Estimativas indiretas realizadas com base em dados censitários e funções de sobrevivência dão conta de que o saldo migratório internacional do país, entre 1980 e 1990, teria sido negativo de 1 a 2 milhões de pessoas (CARVALHO, 1996). No mesmo período, Oliveira et. al. (1996) estimaram uma perda de 1,3 milhão de brasileiros com 20 a 44 anos de idade. Na década seguinte, de 1990, Carvalho e Campos (2006) calcularam que o saldo migratório internacional do Brasil teria sido negativo em 550 mil pessoas.

Cálculos feitos com base em dados consulares, que registram apenas o estoque de residentes no exterior, estimam que entre 2 e 3,7 milhões de brasileiros residiam no exterior no início da década de 2000 (BRASIL, 2008). Já para a Organização Internacional para as Migrações, esse montante variava entre 1 e 3 milhões de indivíduos (OIM, 2010). É importante frisar que esses dados referem-se apenas aos emigrantes e não ao saldo migratório do período.

Apesar de as estimativas mais recentes indicarem um equilíbrio entre entradas e saídas de população (CAMPOS; BORGES; GONÇALVES, 2012), diferentemente do que ocorria no passado, esse equilíbrio seria o resultado de deslocamentos de centenas de milhares de indivíduos nos dois sentidos. Ou seja, longe de ser uma "população fechada", 
atualmente o Brasil estaria inserido em sistemas de migração internacional como região tanto de origem quanto de destino dos fluxos internacionais de pessoas. Embora o volume de imigrantes internacionais tenha aumentado consideravelmente nos últimos anos, as saídas de população permaneceram.

É importante destacar que parcela considerável da imigração internacional recente em direção ao Brasil é composta por retornados. Entre os indivíduos que residiam em país estrangeiro cinco anos antes do último censo (informação de data-fixa), observa-se, por exemplo, que $69 \%$ deles eram brasileiros (IBGE, 2010). Se for considerado o efeito indireto desses deslocamentos, composto por aqueles que, nascidos no exterior, para cá vieram acompanhando os brasileiros retornados, o impacto da migração de retorno seria ainda maior.

Não fosse o Censo Demográfico de 2010 ter captado a saída de 455 mil indivíduos apenas na década anterior à sua realização, o aumento da imigração internacional recente para o Brasil - de bolivianos, haitianos e alguns povos africanos por exemplo - poderia levar-nos a crer, erroneamente, que o país estaria apresentando um saldo migratório internacional positivo considerável.

\section{A emigração internacional segundo o Censo Demográfico 2010}

A maior inovação trazida pelo Censo Demográfico de 2010 com relação ao estudo da migração internacional foi a investigação, em todos os domicílios do país, das pessoas que estavam morando no exterior em 31 de julho de 2010, data de referência do Censo. No caso da presença de emigrantes no domicílio, foram investigados sexo, ano de nascimento, país de residência e data da última partida desses indivíduos para morar no exterior.

Em termos metodológicos, os quesitos utilizados no Censo Demográfico 2010 distanciam-se de outras abordagens utilizadas em censos e pesquisas realizadas em alguns países latino-americanos em anos recentes. A principal diferença é que, no caso brasileiro, não foi indagado se havia alguma relação de parentesco entre o informante e o emigrante. Perguntou-se apenas se alguma pessoa que morava com o entrevistado estava residindo no exterior. A maior parte das experiências internacionais que investigaram esse tipo de informação, muitas delas baseadas nas propostas de Somoza (1977) e Hill (1979), estava ancorada em algum parentesco entre o migrante e o informante. A primeira dessas abordagens, proposta por Somoza em 1977, respalda-se na obtenção, junto às mães, do local de residência de seus filhos. A segunda, proposta por Hill em 1979, investiga o local de residência de irmãos dos entrevistados.

Estudos que avaliam os resultados da aplicação desses quesitos destacam, entretanto, que eles apresentam sérias limitações para estimar o total de emigrantes internacionais de uma região. Como o ponto central nesse tipo de quesito é a existência de um informante na origem para reportar a existência de um emigrante, nos casos em que as informações se baseiam na declaração das mães, é necessário estimar a orfandade e a migração materna. 
Do mesmo modo, no que se refere aos irmãos emigrantes, é preciso estimar a participação dos deslocamentos de todo o grupo familiar no total das migrações, assim como o número médio de irmãos que os potenciais migrantes possuem. Esses ajustes, realizados por meio de modelos demográficos para complementar a parcela dos migrantes não coberta pelas perguntas, muitas vezes geram mais problemas do que resultados, devido à imprecisão dos próprios métodos de ajuste (ZLOTNIK, 1987; BILSBORROW et al., 1997; ZABA, 1987).

Ao analisar de forma detalhada 16 experiências realizadas em censos e pesquisa de países latino-americanos com base nesses quesitos, Zaba (1987) mostra que, em muitos casos, os modelos necessários para complementar essas lacunas chegam, algumas vezes, a dobrar o total de emigrantes captados nas pesquisas.

No caso do quesito utilizado no Brasil em 2010, embora não haja exigência de uma relação de parentesco entre informante e emigrante, sofre-se do mesmo tipo de limitação das abordagens apresentadas: a necessidade de informantes no país para reportar a existência de migrantes. Se, por um lado, a peculiaridade do quesito brasileiro amplia as possibilidades de captação de emigrantes, pois qualquer morador pode prestar a informação sobre eles - não apenas mães ou irmãos -, por outro, ela dificulta a utilização de métodos baseados em relações de parentesco para estimar a parte da migração não captada nas entrevistas. Essa parcela é composta por domicílios onde todos os membros emigraram, pelos casos em que houve falecimento dos que aqui ficaram e pelos indivíduos que moravam sozinhos antes da migração.

Esses fatores podem ter levado à subenumeração de emigrantes, que seria tanto maior quanto mais tempo decorreu entre a migração e o censo. Inversamente, o dado pode ter sofrido sobre-enumeração nos casos em que, no período entre a migração e o censo, houve fragmentação do domicílio e, consequentemente, o emigrante ter sido reportado em todos os domicílios derivados. Possivelmente o primeiro tipo de problema, de erros por falta, tenha superado a questão de erro por excesso decorrente de múltipla contagem de migrantes.

Cabe ressaltar que tais limitações são inerentes a esse tipo de pergunta, sendo, portanto, características dadas a priori à realização da pesquisa. Com base nos resultados, podemos tentar estimar qual foi o grau de cobertura do quesito. 0 fato de o quesito não captar os emigrantes que não deixaram informantes na origem não deve ser configurado como "erro" no resultado da pesquisa, mas sim como limitação metodológica do tipo de investigação.

Embora, com base nessas considerações, possa parecer ter havido negligência em não atrelar a migração a nenhum tipo de relação de parentesco, os resultados das análises dos dados em outros países, conforme discutido, mostram que essa exigência não traria certeza de sucesso na estimação do estoque de migrantes.

Por outro lado, conforme se buscará demostrar, os resultados do Censo Demográfico de 2010 possibilitaram qualificar com uma riqueza de detalhes diversos aspectos relacionados à emigração internacional do Brasil, cujos benefícios superam a imprecisão da estimativa do número de brasileiros residindo no exterior. Adicionalmente, considera-se 
que a amplitude e cobertura alcançadas pela informação do Censo podem ter decorrido, em grande parte, da decisão de "liberar" o emigrante de qualquer tipo de relação de parentesco com o informante, mantendo apenas a necessidade de ter vivido junto desse antes da migração.

\section{Os resultados do censo: possibilidades de análise}

Segundo o Censo Demográfico de 2010, 491.645 indivíduos haviam deixado o país para viver no exterior. No total, 421.737 domicílios reportaram emigrantes (dos 57,3 miIhões de domicílios particulares permanentes recenseados em 2010), com média de 1,17 emigrante por domicílio.

Tomando como referência os tipos de limitação descritos na seção anterior, todos eles provenientes a priori da ida ao campo, o nível de captação obtido surpreende positivamente. Se o estoque de brasileiros residindo no exterior, conforme estimativas (BRASIL, 2008; OIM, 2010), não ultrapassa alguns poucos milhões de indivíduos, o número de saídas registradas - mais de 455 mil apenas na década anterior - pode ser considerado bastante significativo, diferentemente da opinião de Oliveira (2013), por exemplo, que esperava que o quesito tivesse captado mais emigrantes. Contudo, concorda-se com o autor quanto à maior riqueza de detalhes desse tipo de informação, que reside na possibilidade de qualificação da migração e não apenas no total de migrantes captados. Uma análise das características básicas captadas pelo Censo, apresentada em IBGE (2012), mostra que a estrutura etária dos emigrantes estava fortemente concentrada nas idades adultas jovens. Houve pouquíssima captação de idosos e crianças entre os migrantes. A distribuição por sexo também foi bastante equilibrada. A análise do tempo de saída do país mostra que 0 quesito foi mais eficiente para identificar as migrações recentes, o que pode ser explicado tanto por uma questão de memória do entrevistado como pela indefinição do local de residência anterior do emigrante. De acordo com os dados divulgados, $92 \%$ dos emigrantes captados partiram para o exterior na década anterior ao Censo.

Passamos em seguida para a apresentação de alguns temas que podem ampliar consideravelmente o potencial analítico dessas informações. Serão destacados, de forma breve, dois aspectos pouco explorados nos estudos de migração no Brasil, no que se refere ao conjunto da população: as famílias transnacionais e os agrupamentos espaciais de migração.

\section{Famílias transnacionais}

A formação de famílias transnacionais é um dos temas mais instigantes da migração internacional e vem se intensificando recentemente. Essas famílias são definidas, segundo Bryceson e Ulla (2002), como aquelas que vivem separadas fisicamente por uma fronteira internacional, mas que, além de sentimentos de unidade e bem-estar coletivo, continuam mantendo relações efetivas e ininterruptas entre seus membros. A expansão do fenômeno é dada, conforme Eshleman e Bulcroft (2010), pelo aumento das possibilidades de se viver, 
atualmente, de "forma transnacional". 0 que antigamente só ocorria entre os migrantes que habitavam as fronteiras, hoje é possível mesmo entre países distantes.

Isso decorre do desenvolvimento das tecnologias de comunicação e dos meios de transporte. Nesse sentido, os migrantes e suas famílias mantêm contato por meio de remessas imediatas, via sistema financeiro internacional; têm, pelo menos tecnicamente, maiores possibilidades de realizarem visitas ocasionais; e podem se comunicar "em tempo real" via telefone, mensagens eletrônicas, redes sociais digitais e e-mails. Enquanto as migrações do passado separavam os indivíduos por longos períodos ou mesmo por toda a vida, hoje as possibilidades de deslocamento e comunicação fazem com que eles vivam, simultaneamente, em duas realidades distintas. Isso levou Falicov (2007), que estuda os impactos psicológicos da migração internacional, a confrontar as metáforas de "corações partidos" versus "corações duplos".

Os estudos sobre transnacionalismo e migração, na forma como têm sido produzidos atualmente, originaram-se no início da década de 1990, com Glick Shiller, Basch e Blanc-SZanton (1992). Desde então, o conceito de transnacionalismo vem ganhando notoriedade nos estudos de migração. Segundo Guarnizo e Smith (1998), em seu estudo Transnationalism from below, a introdução dessa perspectiva traz ganho analítico considerável ao dar destaque a um fenômeno que, embora não seja algo genuinamente novo no panorama migratório mundial, alcançou particular intensidade em uma escala global no final de século XX.

É importante ressaltar, conforme alertam Portes, Guarnizo e Landolt (1999), que contatos ocasionais, viagens esporádicas e mesmo o envio de remessas por si só não caracterizam uma "prática transnacional”. Para que se justifique a utilidade dessa abordagem é necessário que seja comprovada a existência de compartilhamento de recursos de forma intensa, assim como multiplicação dos tipos de transação e atividades que requeiram um número considerável de viagens e contatos transfronteiriços.

Os dados do Censo 2010 permitem, com riqueza de detalhes, explorar as características dos domicílios de onde os migrantes partiram, além das características dos próprios migrantes investigadas nesse bloco de perguntas. Contudo, não há informações sobre os tipos de relação estabelecidos entre migrantes e não migrantes, em termos de intensidade e frequência de contato.

Acredita-se que as características demográficas dos emigrantes, quando confrontadas com aquelas dos residentes nos domicílios de onde eles partiram, fornecem indícios da possibilidade de ocorrência do fenômeno no Brasil. As limitações impostas pelas poucas perguntas presentes nesse conjunto de quesitos impossibilitam afirmações seguras acerca dos aspectos centrais para a caracterização de famílias transnacionais. Contudo, a concentração da migração em tipos particulares de migrantes, em termos de estrutura etária, assim como dos moradores dos domicílios de onde eles partiram, fornece evidências, ainda que indiretas, de que o fenômeno existe e é numericamente significativo em algumas regiões do Brasil. 
Comparando-se os domicílios que declararam ter havido emigrantes com aqueles em que não há declaração de pessoas nessa situação e analisando-se, por exemplo, as categorias de relação com o responsável pelo domicílio, verifica-se que, nos domicílios com ocorrência de emigração internacional, há $10 \%$ a menos de pessoas declaradas como filhos do que naqueles em que não houve emigração. Por outro lado, o número de netos do responsável era quase duas vezes maior nos domicílios de origem dos emigrantes reportados do que nos demais. Como os percentuais de cônjuges ou companheiros eram bem semelhantes entre os dois tipos, tudo leva a crer que, em grande parte dos domicílios, as migrações foram realizadas por filhos dos responsáveis e do cônjuge que, em alguns casos, deixaram seus filhos sob responsabilidade dos pais.

O Gráfico 1 mostra a estrutura etária dos indivíduos que residem em domicílios de onde partiram migrantes e aquela referente aos emigrantes internacionais. Percebe-se que há um "buraco" na estrutura etária dos domicílios de origem de migrantes, onde se encaixariam aqueles que emigraram, na conformação de um domicílio pré-migração.

\section{GRÁFICO 1}

Distribuição dos moradores nos domicílios de origem dos emigrantes internacionais e dos emigrantes internacionais, segundo a idade

Brasil - 2010

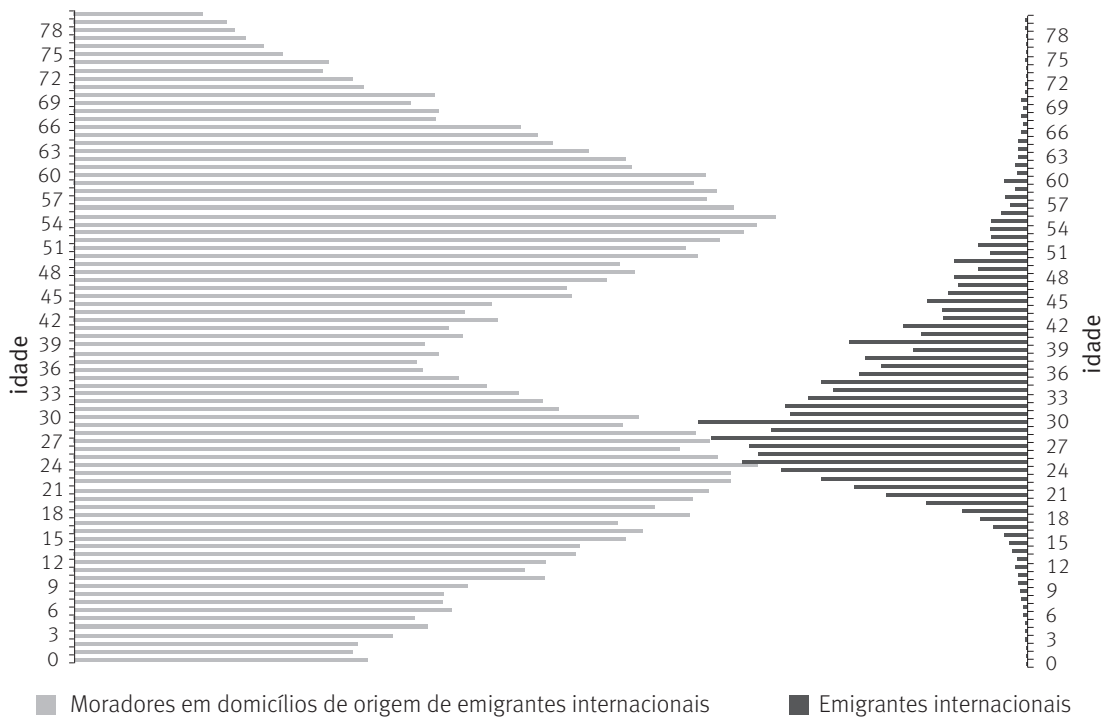

Fonte: IBGE. Censo Demográfico 2010.

Salta aos olhos o fato de o número de crianças residentes nesses domicílios ser extremamente reduzido diante da distribuição etária da população brasileira que, apesar de mostrar redução da proporção de crianças devido à queda da fecundidade, não tem uma entrada tão acentuada na base da pirâmide. 0 percentual de crianças com até 14 anos de idade nos domicílios de origem dos migrantes correspondia a 17,9\%, enquanto nos domicílios sem emigrantes esse valor era de $24,1 \%$. Isso pode ser explicado, pelo menos em parte, pelo 
nascimento de filhos dos emigrantes após a migração. Nesse caso, as crianças não foram declaradas como emigrantes pelo fato de nunca terem residido no domicílio de origem, uma vez que nasceram no exterior. De qualquer forma, os dados sugerem uma forte correlação entre migração e baixo número de crianças reportadas. Outro aspecto importante é o hiato de idade observado entre as duas distribuições etárias representadas no Gráfico 1. Uma das possíveis explicações seria um "erro de memória" do informante em relação à idade do migrante, como se esse tivesse a idade em que migrou “congelada” após a migração.

Por outro lado, a proporção de idosos nos domicílios de onde partiram os migrantes foi de $24,1 \%$. Ou seja, um quarto dos moradores desses domicílios possuíam 60 anos ou mais, enquanto nos domicílios sem emigrantes esse percentual era de 10,4\%.

A importância do estudo dos domicílios de onde partiram o migrante também é relevante pelo fato de estes terem acesso privilegiado a recursos disponíveis nos locais de residência dos emigrantes, na forma de bens, remessas financeiras, ideias e informações vindas do exterior. Análises detalhadas das características desses domicílios têm muito a contribuir para o entendimento das estratégias familiares de migração, como, por exemplo, os dados de rendimento, que podem indicar o recebimento de remessas ou mesmo dos bens materiais do domicílio, como posse ou não de imóvel, típica fonte de investimento de renda obtida no exterior (MARTES; SOARES, 2006)

\section{Agrupamentos de emigração internacional}

Uma característica marcante da migração que pode ser mensurada com base nesses quesitos é sua alta seletividade espacial em relação às localidades que participam dos fluxos migratórios. A ideia de seletividade da migração, fartamente discutida na literatura, ${ }^{2}$ pode se dar em termos tanto de atributos dos migrantes quanto dos locais envolvidos com a migração. Em termos espaciais, isso levaria à concentração das regiões de origem e destino dos migrantes. As redes de migração, além de uma dimensão social, conformam também uma dimensão espacial (MATOS, 2010).

Com base nos quesitos de emigração do Censo 2010, em um estudo em que buscamos delinear os agrupamentos (clusters) de emigração internacional do Brasil (CAMPOS; MACEDO, 2014), identificamos uma alta concentração de domicílios de onde partiram migrantes em poucas regiões. Com base nas análises realizadas houve o delineamento de nove agrupamentos de emigração internacional, nos quais estavam inseridos 338 municípios, conforme apresentado na Figura 1.

\footnotetext{
${ }^{2}$ Para uma síntese da relação entre seletividade e migração, ver Campos (2015).
} 
FIGURA 1

Agrupamentos de emigração internacional

Brasil - 2010

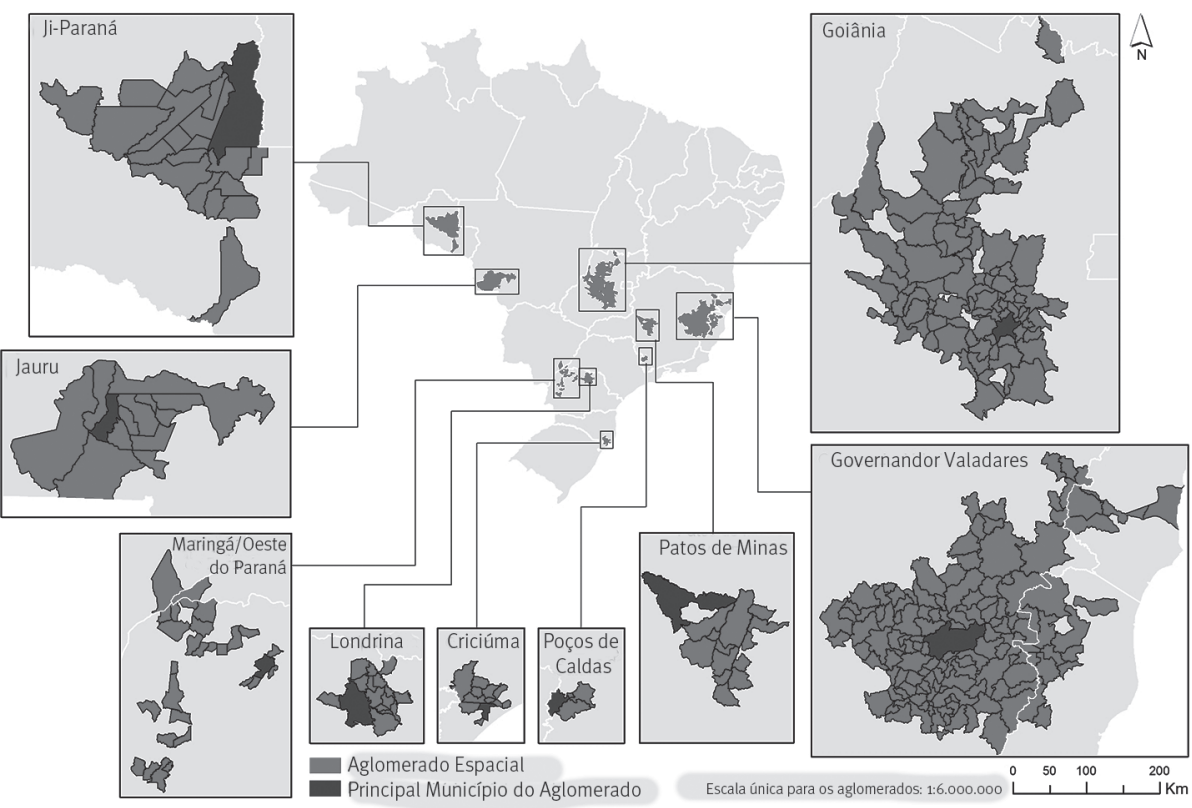

Fonte: Campos e Macedo (2014)

Com relação às regiões de destino, embora os dados não permitam uma caracterização com o mesmo nível de detalhes que as regiões de origem, os resultados mostram que Estados Unidos, Portugal, Espanha, Japão e Itália, nessa ordem, concentravam, juntos, mais de 60\% dos migrantes (IBGE, 2010).

As análises realizadas por Jorgensen (2017), que adicionam uma dimensão temporal para analisar o comportamento dos migrantes quanto à escolha dos países de destinos, mostram que o padrão dos deslocamentos vem se alterando ao longo do tempo, quando os Estados Unidos perdem participação para a migração realizada em direção a Portugal sem, contudo, diminuir a concentração dos migrantes em poucos países.

Assim como no caso das famílias transnacionais, a análise dos agrupamentos espaciais de emigração mostra as inúmeras possibilidades de uso dos dados de emigração internacional do censo para estudo de aspectos pouco conhecidos, pelo menos em nível nacional, da migração recente de brasileiros para o exterior. Como essas localidades apresentam "acesso" diferenciado a regiões localizadas em outros países, acabam sendo espaços especiais no Brasil, cujas características o Censo 2010 permite delinear com clareza. 


\section{Afinal, vale a pena manter, nos censos demográficos, as perguntas sobre ex-moradores residindo no exterior?}

Retomando a pergunta do título, não resta dúvida de que o interesse, político ou científico, de se conhecer melhor as características da emigração internacional do Brasil justifica a manutenção desses quesitos no censo demográfico por um simples motivo: essa é a única fonte de informação disponível em nível nacional sobre o tema no país.

Apesar de a saída de brasileiros para outros países ocorrer de forma considerável desde os anos 1980, apenas em 2010 foi inserido um quesito no censo para investigar o fenômeno. Como mostram os resultados do quesito, as saídas de população se mantiveram, com intensidade, na primeira década do presente século. A conjuntura social e econômica atual pode inclusive ter intensificado a emigração pós-censo. Além da recessão econômica brasileira, a principal região de origem de emigrantes do país, Governador Valadares, passa por uma crise hídrica decorrente do rompimento da barragem de Mariana, que pode também ter gerado efeito adicional sobre as emigrações.

Em suma, os resultados divulgados ampliaram consideravelmente as possibilidades de estudo das migrações internacionais do Brasil. Com base neles pode-se fazer, pela primeira vez em nível nacional, uma caracterização precisa tanto dos emigrantes internacionais como dos domicílios de onde eles partiram. 0 presente ensaio buscou demonstrar as possiblidades de estudo de aspectos pouco conhecidos, mas de suma importância para se aprofundar o conhecimento sobre migração internacional no Brasil e na América Latina.

Acredita-se que o quesito poderia ser aprimorado com pequenos ajustes, como a mudança do texto da questão que investiga o tempo de saída do país: no lugar de indagar sobre a "última partida" - que pode levar o informante a confundir a partida para viver no exterior e os retornos ao exterior após visitas ao Brasil -, poder-se-ia perguntar "em que ano o indivíduo partiu para viver no exterior”. Além disso, uma informação que enriqueceria ainda mais as análises do fenômeno seria a investigação da posição do emigrante na família ou de sua relação com o responsável pelo domicílio.

Não é objetivo do presente ensaio gerar um veredicto científico que justifique a presença ou não de perguntas no censo, processo que envolve complexas negociações contingenciadas por questões orçamentárias, políticas e operacionais. A luta que temos travado nos últimos anos é municiar aqueles que defendem a permanência do quesito com argumentos que extrapolam a avalição do quesito "apenas" pelo aspecto quantitativo (número de emigrantes captados).

\section{Referências}

BILSBORROW, R. E.; HUGO, G.; OBERAI, A. S.; ZLONIK, H. International migration statistics: guidelines for improving data collection systems. Geneva: International Labour Office, 1997.

BRASIL. Ministério das Relações Exteriores. Brasileiros no mundo: estimativas. Brasília, DF, 2008. 
BRYCESON, D. F.; ULLA, V. The transnational family: new European frontiers and global networks. Oxford: Berg, 2002.

CAMPOS, M. B. Seletividade e migração. In: BRUNO, M. (Org.). População, espaço e sustentabilidade: contribuições para o desenvolvimento do Brasil. 1. ed. Rio de Janeiro: IBGE, 2015. p. 187-202.

CAMPOS, M. B.; BORGES, G. M.; GONÇALVES, L. C. Estimativas de migração internacional no Brasil: reversão do saldo migratório internacional negativo. In: XVIII ENCONTRO NACIONAL DE ESTUDOS POPULACIONAIS. Anais... Águas de Lindóia/SP: Abep, 2012.

CAMPOS, M. B.; MACEDO, D. R. Agrupamentos de emigração internacional no Brasil: o papel das redes sociais na formação dos espaços de emigração. Geografia, Rio Claro, v. 39, n. 2, p. 257-272, maio/ago. 2014.

CARVALHO, J. A. M. de; CAMPOS, M. B. A variação do saldo migratório internacional do Brasil. Estudos Avançados, São Paulo, v. 20, n. 57, p. 55-58, 2006.

CARVALHO, J. A. M. de. O saldo dos fluxos migratórios internacionais no Brasil na década de 80: uma tentativa de estimação. Revista Brasileira de Estudos de População, Rio de Janeiro, v. 13, n. 1, p. 3-14, 1996.

ESHLEMAN, J. R.; BULCROFT, R. A. The family. 12. ed. New York: Pearsons, 2010.

FALICOV, C. J. Working with transnational immigrants: expanding meanings of family, community, and culture. Family Process, v. 46, n. 2, 2007.

GLICK SCHILLER, N.; BASCH, L.; BLANC-SZANTON, C. Transnationalism: a new analytic framework for understanding migration. Annals New York Academy of Sciences, v. 645, n. 1, 1992.

GUARNIZO, L. E.; SMITH, M. P. The locations of transnationalis. In: SMITH, M. P.; GUARNIZO, L. E. (Ed.). Transnationalism from below. Comparative urban and community research. New Brunswick, NJ: Transaction Publishers, v. 6, 1998.

HILL, K. Estimación de la emigración por edades a partir de la información sobre residencia de hermanos. Notas de Población, Santiago de Chile, n. 21, 1979.

IBGE - Instituto Brasileiro de Geografia e Estatística. Censo demográfico 2010. Rio de Janeiro, 2010.

MARTES, A. C. B.; SOARES, W. Remessas de recursos dos imigrantes. Estudos Avançados, São Paulo, v. 20, n. 57, 2006.

MATOS, R. E. (Org.). Espacialidades em rede: população, urbanização e migração no Brasil contemporâneo. Belo Horizonte: C/Arte, 2005.

JOHANSSEN, N. Migração internacional, remessas, família e gênero: o caso de Governador Valadares. Dissertação (Mestrado em Demografia) - Universidade Federal de Minas Gerais, Belo Horizonte, 2017.

OIM - Organização Internacional para as Migrações. Perfil migratório do Brasil 2009. Genebra: OIM, 2010.

OLIVEIRA, A. T. R. et al. Notas sobre a migração internacional no Brasil na década de 80. In: PATARRA, N. L. (Coord.). Migrações internacionais: herança XX, agenda XXI. Campinas: Funap, 1996.

Um panorama da migração internacional a partir do Censo Demográfico de 2010.

Revista Interdisciplinar de Mobilidade Humana, v. 21, p. 195-210, 2013. 
PORTES, A.; GUARNIZO, L. E.; LANDOLT, P. The study of transnationalism: pitfalls and promise of an emergent research. Ethnic and Racial Studies, v. 22, n. 2, Mar. 1999.

SOARES, W.; FAZITO, D. Capital social, análise de redes e os mecanismos intermediários do sistema migratório Brasil/EUA. Geografias, Belo Horizonte, v.10, n.1, p. 27-41, 2010.

SOMOZA, J. Una idea para estimar la población emigrante por sexo y edad en el censo de un país. Notas de Población, Santiago de Chile, n. 15, 1977.

VERTOTEC, S. Conceiving and researching transnationalism. Ethnic and Racial Studies, v. 22, n. 2, 1999.

ZABA, B. The indirect estimation of migration: a critical review. International Migration Review, v. 21, n. 4, p. 1395-445, 1987.

ZLOTNIK, H. La utilizacion de informacion sobre residencia de parientes para medir la emigracion internacional. Notas de Poblacion, v. 15, n. 45, p. 25-65, Dec. 1987

\section{Sobre 0 autor}

Marden Campos é economista, com doutorado em demografia. Professor do Departamento de Sociologia da Universidade Federal de Minas Gerais (UFMG).

\section{Endereço para correspondência}

Departamento de Sociologia

Faculdade de Filosofia e Ciências Humanas, sala 4166

Av. Pres. Antônio Carlos, 6627, Pampulha

31270-901 - Belo Horizonte-MG, Brasil

\section{ANEXO 1}

\section{Quesitos de emigração internacional do Censo Demográfico 2010}

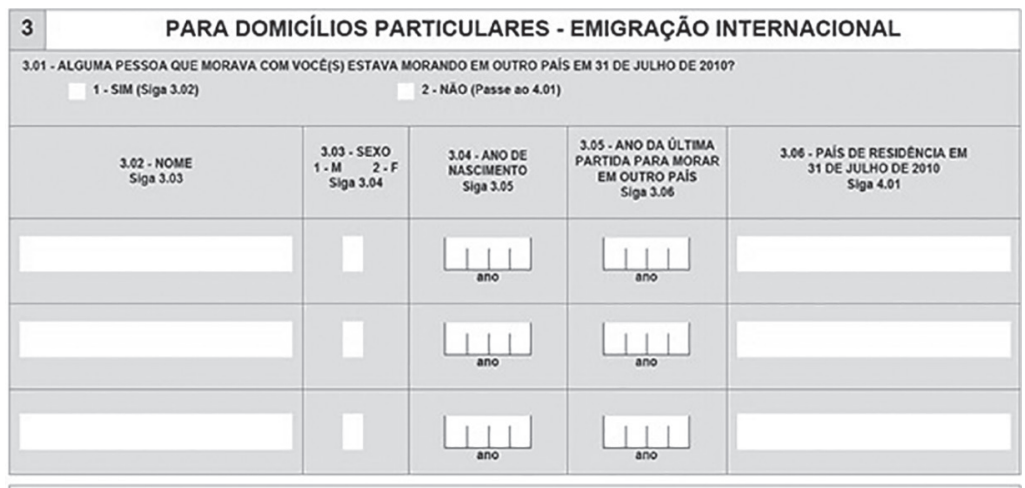

Recebido para publicação em 07/08/2017

Aceito para publicação em 10/04/2018 